\title{
Article
}

\section{Adsorption of Rare-Earth Metal Ions on Natural Banana Fiber}

\author{
Tetsuto KAJIYAMA ${ }^{1 *}$, Kensuke ARAI², Satoshi OHMURO², Takuya MARUYAMA ${ }^{3}$, \\ Chika SHIMOSE 3 , Satomi MAKINO ${ }^{3}$, Shuhei TAKASE ${ }^{3}$ and Hisao KOKUSEN ${ }^{3}$ \\ ${ }^{1}$ Environmental Technology Group, Division II, Research and Development Department, Tokyo Metropolitan Industrial \\ Technology Research Institute, 2-4-10 Aomi, Koto, Tokyo 135-0064, Japan \\ ${ }^{2}$ Division of Physical and Analytical Chemistry, Nihon Pharmaceutical University, Komuro 10281, Ina, Kitaadachi, \\ Saitama 362-0806, Japan \\ ${ }^{3}$ Department of Chemistry, Faculty of Education, Tokyo Gakugei University, 4-1-1 Nukuikitamachi, Koganei, \\ Tokyo 184-0015, Japan
}

(Manuscript received April 6, 2018; accepted June 14, 2018)

\begin{abstract}
The adsorption properties of banana fibers for rare-earth metal ions $\left(\mathrm{La}^{3+}, \mathrm{Gd}^{3+}, \mathrm{Tm}^{3+}, \mathrm{Pr}^{3+}, \mathrm{Tb}^{3+}, \mathrm{Yb}^{3+}\right.$, $\mathrm{Nd}^{3+}, \mathrm{Dy}^{3+}, \mathrm{Lu}^{3+}, \mathrm{Sm}^{3+}, \mathrm{Ho}^{3+}, \mathrm{Eu}^{3+}$, and $\mathrm{Er}^{3+}$ ) were investigated, and the concentrations of metal ions were measured by using an inductively coupled plasma optical emission spectrometer. The $\mathrm{pH}$ value of the aqueous phase was measured using a $\mathrm{pH}$ meter equipped with glass electrodes. Over $70 \%$ of all the metal ions were adsorbed on non-treated banana fiber at $\mathrm{pH}$ values ranging from 2.0 to 6.0. On the other hand, using alkali-treated banana fiber, the adsorption ratio for rare-earth metal ions increased with $\mathrm{pH}$. The reaction equation for the alkali-treated banana fiber system was investigated by the slope analysis between logarithmic distribution ratio and $\mathrm{pH}$. The results suggest that not only the hydroxy groups originated from the interaction between cellulose and metal ions but also other negative ions might be involved in the ionexchange reaction in the alkali-treated banana fiber. Such distinct behavior raises the possibility of the utilization of banana fibers in the separation and adsorption of metal ions.
\end{abstract}

Keywords: Banana fiber, Rare-earth, Ion exchange, Metal ion adsorbent

\section{Introduction}

Since over a billion banana stalks are thrown away every year, banana fiber has recently attracted attention as an abundant inedible natural resource, and its effective reuse as a valuable biomass resource has been studied ${ }^{1-3)}$. Additionally, the investigation of banana fibers as an adsorbent for dyes has been reported. Thus, Gupta et al. described the use of banana fibers as an adsorbent for the removal of malachite green dye $e^{4)}$, and Haris and Sathasivam reported the removal of methyl red from aqueous solutions using banana fibers ${ }^{5,6)}$. However, to the best of our knowledge, the investigation of banana fibers or chemically modified banana fibers as an adsorbent for various metal ions has not been reported to date. For the removal and separation of metal ions, several methods are available, including ion exchange and solvent extraction. In this context, the development of environmentally friendly ion-exchange methods and the use of chelate materials for the collection and separation of metal ions are attracting growing attention from many researchers ${ }^{7-11)}$. Recently, we evaluated the adsorption properties of modified banana fiber for transition metal ions ${ }^{12)}$ and rare metal ions ${ }^{13)}$. The adsorption of cesium and strontium ions was studied using banana fibers as adsorbents ${ }^{14)}$.

Rare and rare-earth metals are important in many fields of advanced materials science; moreover, their applications in material industries have significantly increased. In the present study, the adsorption properties of banana fibers for rare-earth

* Corresponding author

E-mail: kajiyama.tetsuto@iri-tokyo.jp 
metal ions were evaluated. The reaction equation in alkalitreated banana fiber system was investigated by the slope analysis between logarithmic distribution ratio and $\mathrm{pH}$. From the results obtained, banana fibers can be envisaged as good candidates for the adsorption of metal ions.

\section{Experimental}

\subsection{Materials}

Banana fiber was obtained from the Republic of the Philippines. Standard solutions for each metal ion and other chemicals were purchased from Wako Pure Chemical Industries Co., Ltd, Osaka, Japan and used without further purification.

\subsection{Alkali-treated banana fiber}

About $7 \mathrm{~g}$ of the banana fiber was packed into a $200 \mathrm{~mm}$ long column of $10 \mathrm{~mm}$ diameter. Alkali treatment was performed by pumping $2 \mathrm{~mol} \mathrm{dm}^{-3}$ sodium hydroxide solution into the column at a flow mass of $1.5 \mathrm{dm}^{3}$.

\subsection{Adsorption of rare-earth metal ions on banana fibers}

Individual aqueous solutions containing $5.0 \times 10^{-5} \mathrm{~mol} \mathrm{dm}^{-3}$ of the metal ions $\mathrm{La}^{3+}, \mathrm{Gd}^{3+}, \mathrm{Tm}^{3+}, \mathrm{Pr}^{3+}, \mathrm{Tb}^{3+}, \mathrm{Yb}^{3+}, \mathrm{Nd}^{3+}, \mathrm{Dy}^{3+}$, $\mathrm{Lu}^{3+}, \mathrm{Sm}^{3+}, \mathrm{Ho}^{3+}, \mathrm{Eu}^{3+}$, and $\mathrm{Er}^{3+}, 1.0 \times 10^{-2} \mathrm{~mol} \mathrm{dm}{ }^{-3}$ sodium sulfate, and $1.0 \times 10^{-2} \mathrm{~mol} \mathrm{dm}^{-3}$ acetic acid, chloroacetic acid, or 2-morpholinoethanesulfonic acid monohydrate (MES) were prepared. Next, $10 \mathrm{~cm}^{3}$ of each solution was put into plastic tubes along with $0.1 \mathrm{~g}$ of the metal ion adsorbent. These tubes were shaken for 48 hour at room temperature. After the reaction was complete, the mixed solutions were filtered. The concentration of the metal ions was measured using an inductively coupled plasma optical emission spectrometer (ICPOES). The $\mathrm{pH}$ value of the aqueous phase was measured using a $\mathrm{pH}$ meter equipped with glass electrodes.

\section{Results and Discussion}

3.1 Adsorption properties of non-treated and alkali-treated banana fibers for rare-earth metal ions

Adsorption experiments were performed using non-treated and alkali-treated banana fibers.

The adsorption ratios of the rare-earth metal ions are shown in Fig. 1 and Fig. 2. Over $70 \%$ of all the metal ions were adsorbed at $\mathrm{pH}$ values ranging from 2.0 to 6.0 using non-treated banana fiber. On the other hand, the adsorption ratios of the rare-earth metal ions using alkali-treated banana fiber increased up to a $\mathrm{pH}$ value of about 5.0. From $45 \%$ to $99 \%$ of all the metal ions were adsorbed at $\mathrm{pH}$ values below 2.0; however, not all the metal ions were adsorbed up to this point using alkali-treated banana fiber (Fig. 3 and Fig. 4). These results demonstrate the feasibility of the use of banana fibers for rare-earth metal ion adsorption; however, the rare-earth metal ions could not be separated from each other by either non-alkali or alkali-treated banana fibers.

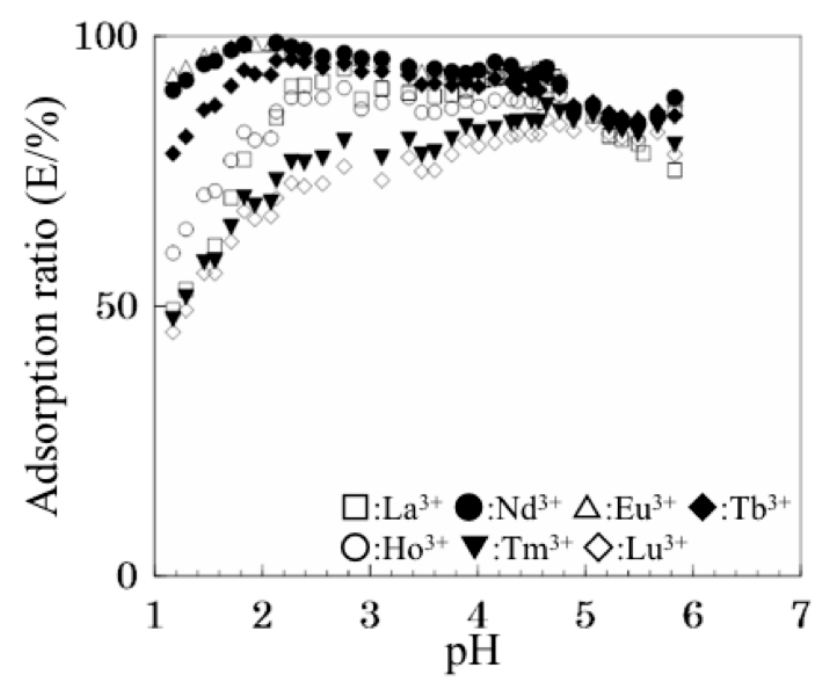

Fig. 1 Effects of $\mathrm{pH}$ on the adsorption of $\mathrm{La}^{3+}, \mathrm{Nd}^{3+}, \mathrm{Eu}^{3+}$, $\mathrm{Tb}^{3+}, \mathrm{Ho}^{3+}, \mathrm{Tm}^{3+}$, and $\mathrm{Lu}^{3+}$ using non-treated banana fiber.

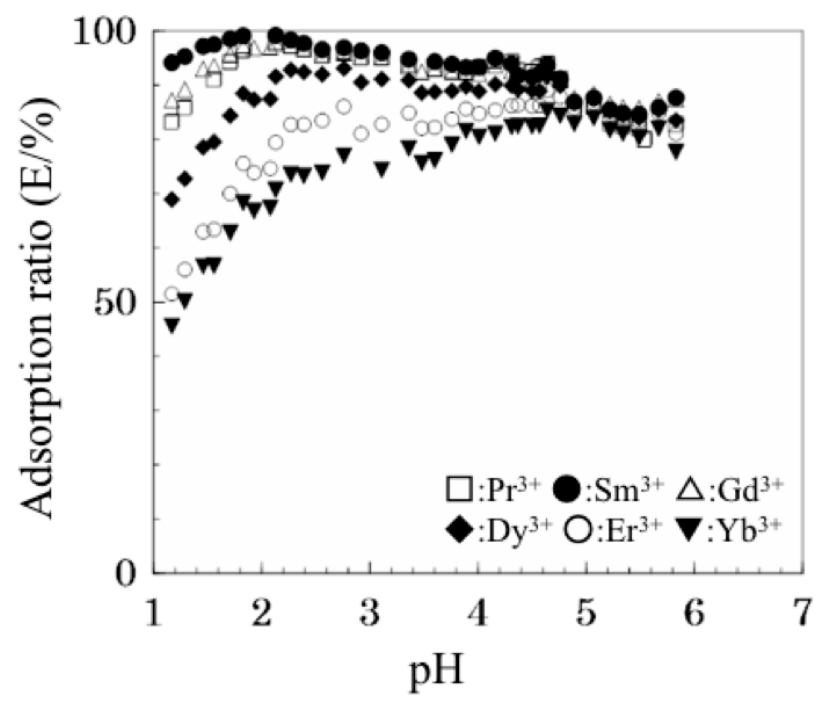

Fig. 2 Effects of $\mathrm{pH}$ on the adsorption of $\mathrm{Pr}^{3+}, \mathrm{Sm}^{3+}, \mathrm{Gd}^{3+}$, $\mathrm{Dy}^{3+}, \mathrm{Er}^{3+}$, and $\mathrm{Yb}^{3+}$ using non-treated banana fiber.

In general, banana fibers are composed of approximately $9 \%$ lignin, 39\% hemicellulose, and $43 \%$ cellulose, among other compounds ${ }^{15,16)}$. The alkali treatment removed the lignin and hemicellulose present in the non-treated banana fiber. In our previous study, we reported the SEM images of the surfaces of the banana fibers before and after being subjected to alkaline treatment ${ }^{13}$. The smooth surfaces of the banana fibers were found to adopt a wavy morphology after alkali treatment, which was indicative of the presence of more hydroxy groups stemming from the cellulose on the surfaces of the banana fibers. Furthermore, lignin could be identified in the banana fibers by using FT-IR. The $\mathrm{C}=\mathrm{C}$ groups of lignin were found to give rise to different bands around $1620 \mathrm{~cm}^{-1}$ in the spectra of non- 
treated and alkali-treated banana fibers. Since lignins, along with other functional groups, are considered the adsorption sites of metal ions in the banana fibers, and most all the lignin content was removed by sodium hydroxide treatment ${ }^{17)}$, the difference in the lignin content could be invoked to explain the observed differences in the adsorption behavior of non-treated and alkali-treated banana fibers.

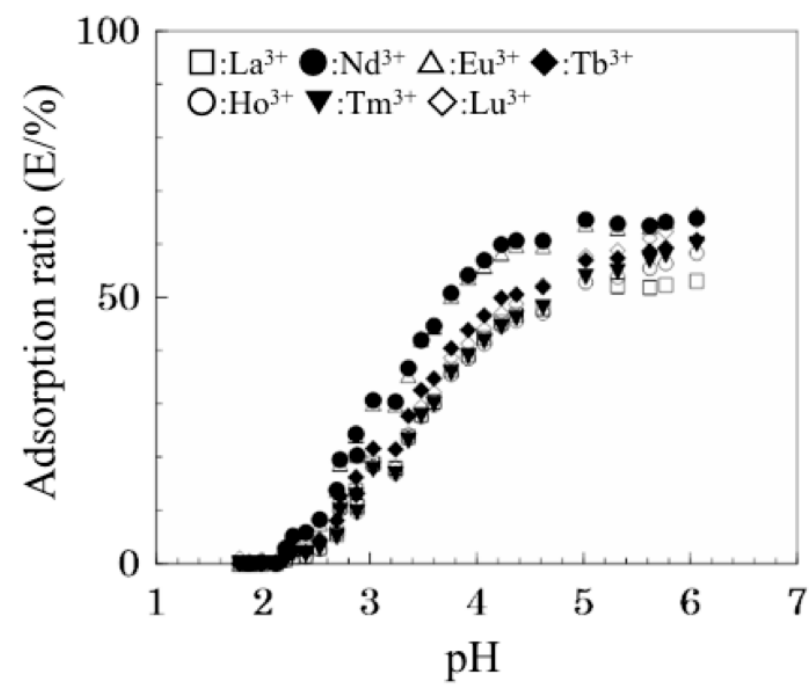

Fig. 3 Effects of $\mathrm{pH}$ on the adsorption of $\mathrm{La}^{3+}, \mathrm{Nd}^{3+}, \mathrm{Eu}^{3+}$, $\mathrm{Tb}^{3+}, \mathrm{Ho}^{3+}, \mathrm{Tm}^{3+}$, and $\mathrm{Lu}^{3+}$ using alkali-treated banana fiber.

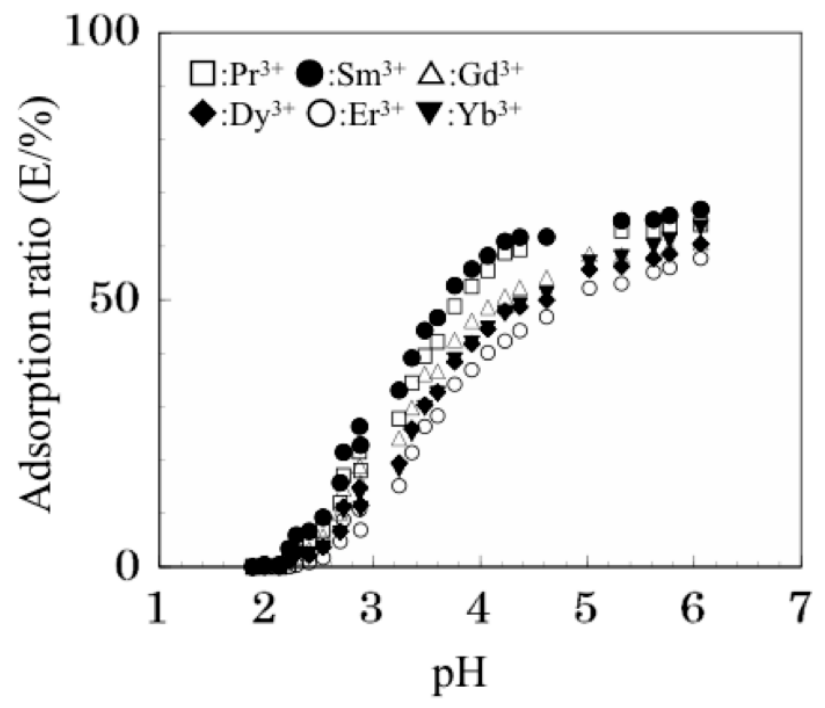

Fig. 4 Effects of $\mathrm{pH}$ on the adsorption of $\mathrm{Pr}^{3+}, \mathrm{Sm}^{3+}, \mathrm{Gd}^{3+}$, $\mathrm{Dy}^{3+}, \mathrm{Er}^{3+}$, and $\mathrm{Yb}^{3+}$ using alkali-treated banana fiber.

\subsection{Behavior of alkali-treated banana fiber in the adsorption of rare-earth metal ions}

The half-adsorption $\mathrm{pH}$ values $\left(\mathrm{pH}_{1 / 2}\right)$, defined as the $\mathrm{pH}$ at which $50 \%$ of the metal ion content is adsorbed using alkalitreated banana fiber, are shown in Table 1. Here, the equation
Table 1 Half-adsorption $\mathrm{pH}$ values and slopes

\begin{tabular}{ccc}
\hline & $\mathrm{pH}_{1 / 2}$ value & Slope \\
\hline $\mathrm{La}^{3+}$ & $-^{\mathrm{a}}$ & 1.85 \\
$\mathrm{Pr}^{3+}$ & 3.84 & 1.51 \\
$\mathrm{Nd}^{3+}$ & 3.75 & 1.10 \\
$\mathrm{Sm}^{3+}$ & 3.67 & 1.34 \\
$\mathrm{Eu}^{3+}$ & 3.76 & 1.54 \\
$\mathrm{Gd}^{3+}$ & 4.15 & 1.89 \\
$\mathrm{~Tb}^{3+}$ & 4.37 & 1.63 \\
$\mathrm{Dy}^{3+}$ & 4.62 & 1.56 \\
$\mathrm{Ho}^{3+}$ & 4.82 & 1.91 \\
$\mathrm{Er}^{3+}$ & 4.82 & 1.94 \\
$\mathrm{Tm}^{3+}$ & 4.83 & 1.74 \\
$\mathrm{Yb}^{3+}$ & 4.49 & 1.42 \\
$\mathrm{Lu}^{3+}$ & 4.49 & 1.43 \\
\hline
\end{tabular}

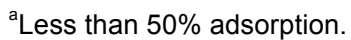

of the reaction between rare-earth metal ions and alkali-treated banana fiber can be expressed as

$$
\begin{aligned}
& n(\mathrm{R}-\mathrm{OH})+\mathrm{M}^{3+} \rightleftarrows(\mathrm{R}-\mathrm{O})_{n} \mathrm{M}^{(\mathrm{n}-3)-}+n \mathrm{H}^{+} \\
& \left(n(\mathrm{R}-\mathrm{OH}) \rightleftarrows n(\mathrm{R}-\mathrm{O})^{-}+n \mathrm{H}^{+}\right)
\end{aligned}
$$

where $\mathrm{R}-\mathrm{OH}$ represents the hydroxy group originated from the cellulose. The selectivity coefficient $(K)$ was calculated from Eq. (1) as follows:

$$
\begin{aligned}
& K=\left[(\mathrm{R}-\mathrm{O})_{n} \mathrm{M}^{(\mathrm{n}-3)-}\right]\left[\mathrm{H}^{+}\right]^{n} /\left[\mathrm{M}^{3+}\right][\mathrm{R}-\mathrm{OH}]^{n} \\
& K=D\left(\left[\mathrm{H}^{+}\right]^{n} /[\mathrm{R}-\mathrm{OH}]^{n}\right) \\
& \left(D=\left[(\mathrm{R}-\mathrm{O})_{n} \mathrm{M}^{(\mathrm{n}-3)-}\right] /\left[\mathrm{M}^{3+}\right]\right)
\end{aligned}
$$

where $\left[\mathrm{M}^{3+}\right]$ represents the moles of metal ion per $1 \mathrm{~cm}^{3}$ of aqueous solution. From Eq. (3), the reaction equation in the alkali-treated banana fiber system was investigated by the slope analysis between the logarithmic distribution ratio $(\log D)$ and $\mathrm{pH}$.

$$
\begin{aligned}
& \log K=\log D+n \log \left[\mathrm{H}^{+}\right]-n \log [(\mathrm{R}-\mathrm{OH})] \\
& \log D=n \mathrm{pH}+\mathrm{constant}
\end{aligned}
$$

where constant represent $\log K+n \log [(\mathrm{R}-\mathrm{OH})]+n \mathrm{pH}$ under constant $\mathrm{pH}$. The results of the slope analysis between $\log D$ and $\mathrm{pH}$ for the adsorption of $\mathrm{Pr}^{3+}, \mathrm{Eu}^{3+}, \mathrm{Dy}^{3+}, \mathrm{Yb}^{3+}, \mathrm{Ho}^{3+}$, and $\mathrm{Gd}^{3+}$ on alkali-treated banana fiber are shown in Fig. $\mathbf{5}$ as representative examples. In all plots, straight lines with slopes between 1.10 and 1.94 were obtained, which suggests that, in the ion-exchange reaction with alkali-treated banana fiber, not only the hydroxy groups originated from the interaction between cellulose and metal ions might be involved, but also other negative ions such as sulfate (Fig. 6). To confirm this hypothesis, further studies on the exact adsorption behavior of alkali-treated banana fiber for metal ions are required.

On the other hand, we observed in our previous study on the adsorption and desorption of $\mathrm{Cs}^{+}$and $\mathrm{Sr}^{2+}$ by batch method using non-treated banana fiber that the desorption reaction and site of monovalent $\mathrm{Cs}^{+}$and divalent $\mathrm{Sr}^{2+}$ were different ${ }^{14)}$. The adsorption behavior of non-treated banana fiber for rare-earth metal ions will be the focus of future studies. 

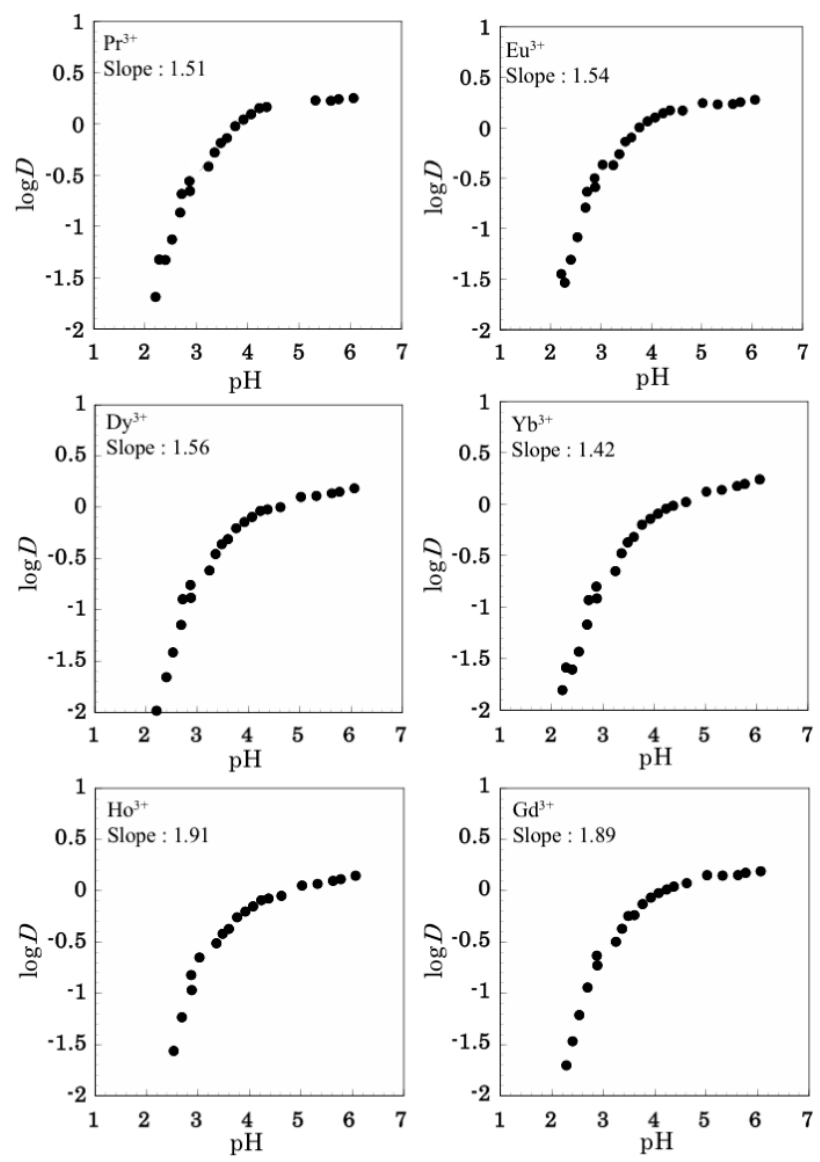

Fig. 5 Plots of $\log D$ of metal ions as a function of $\mathrm{pH}$ in the alkali-treated banana fiber system.
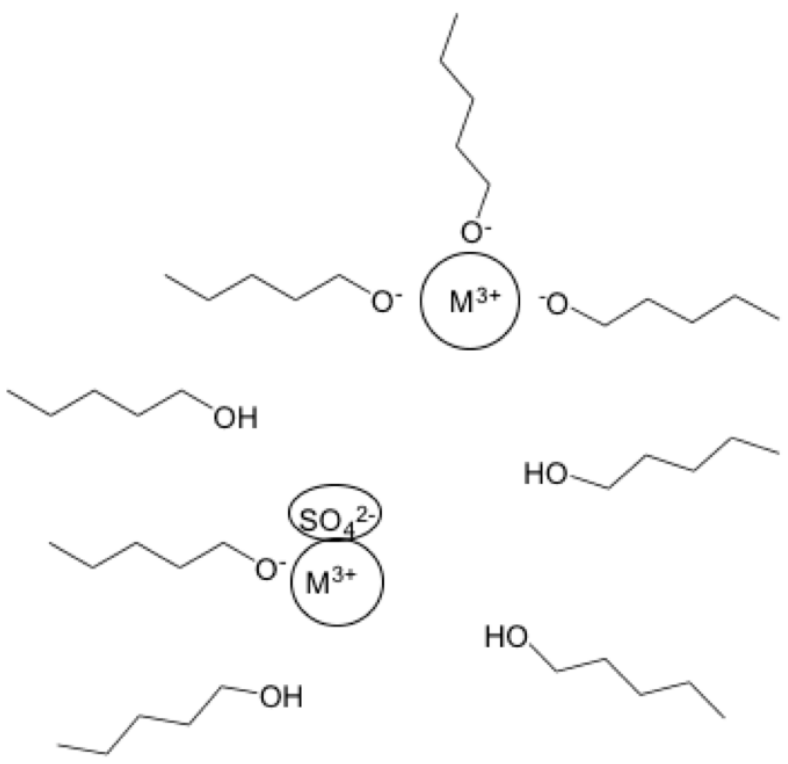

Fig. 6 Adsorption behavior of alkali-treated banana fiber and metal ions.

\section{Conclusion}

Over $70 \%$ of all the metal ions were adsorbed at $\mathrm{pH}$ values ranging from 2.0 to 6.0 using non-treated banana fiber. In contrast, the adsorption ratios using alkali-treated banana fiber increased up to a $\mathrm{pH}$ value of about 5.0.

The reaction equation of rare-earth metal ions and alkalitreated banana fiber was investigated. Straight lines with slopes between 1.10 and 1.94 were obtained, which suggests that not only the hydroxy groups originated from the reaction between cellulose and metal ions but also other negative ions such as sulfate might be involved in the ion-exchange reaction.

Although the rare-earth metal ions could not be separated from each other by either non-alkali or alkali-treated banana fibers, the results obtained in this work demonstrate the potential of banana fibers as adsorbents of rare-earth metal ions.

\section{Acknowledgment}

This research was supported by the Environment Research and Technology Development Fund (3K143003) of the Ministry of the Environment, Japan.

\section{References}

1) R. Zuluaga, J.-L. Putaux, A. Restrepo, I. Mondragon and P. Ganan, Cellulose, 14, 585 (2007).

2) T. Yasuda and T. Kajiyama, Seikei-Kakou, 25, 592 (2013) (in Japanese).

3) T. Kajiyama, T. Yasuda, S. Mimoto, K. Shimizu, K. Hayashi, T. Yamanaka and M. Murakami, Int. Polym. Process., 28, 58 (2013).

4) N. Gupta, A.K. Kushwaha and M.C. Chattopadhyaya, J. Chem. Pharm. Res., 3, 284 (2011).

5) M.R.H.M. Haris and K. Sathasivam, Am. J. Appl. Sci., 6, 1690 (2009).

6) M.R.H.M. Haris and K. Sathasivam, Arch. Appl. Sci. Res., 2, 209 (2010).

7) K. Fujimoto, N. Tobito and S. Ito, J. Ion Exchange, 25, 12 (2014).

8) Y. Asari, N. Shoji, K. Miyoshi, D. Umeno and K. Saito, J. Ion Exchange, 22, 53 (2011).

9) S. Usada, R. Liu, Y. Wei, Y. Xu, H. Yamazaki and Y. Wakui, J. Ion Exchange, 21, 35 (2010).

10) S. Oshima, S. Hirayama, K. Kubono and H. Kokusen, J. Ion Exchange, 18, 360 (2007).

11) M. Iiyama, H. Kokusen, S. Tsurubou and Y. Komatsu, $J$. Ion Exchange, 18, 440 (2007).

12) T. Kajiyama, S. Sakai, J. Inoue and H. Kokusen, J. Ion Exchange, 25, 155 (2014).

13) T. Kajiyama, S. Sakai, J. Inoue, T. Yoshino, S. Ohmuro, K. Arai and H. Kokusen, J. Ion Exchange, 27, 57 (2016).

14) T. Kajiyama and H. Kokusen, J. Ion Exchange, 27, 8 (2016).

15) N. Venkateshwaran and A. Elayaperumal, J. Reinf. Plast. 
Comp., 29, 2387 (2010).

16) Nilza, G. J-Smith, G. Jr. Virgo and V.-E. Buchanan, Mater. Char., 59, 1273 (2008).

17) T. Kajiyama, K. Arai and H. Kokusen, Proceedings of ISEC2017, 264 (2017). 